\title{
Social Media Engagement and Influenza Vaccination During the COVID-19 Pandemic: Cross-sectional Survey Study
}

Arriel Benis ${ }^{1,2}, \mathrm{PhD}$; Anna Khodos ${ }^{1}$, BSc; Sivan Ran ${ }^{1}$, BSc; Eugene Levner ${ }^{3}$, PhD; Shai Ashkenazi ${ }^{4}, \mathrm{MD}, \mathrm{MSc}$

${ }^{1}$ Faculty of Industrial Engineering and Technology Management, Holon Institute of Technology, Holon, Israel

${ }^{2}$ Faculty of Digital Technologies in Medicine, Holon Institute of Technology, Holon, Israel

${ }^{3}$ Faculty of Sciences, Holon Institute of Technology, Holon, Israel

${ }^{4}$ Adelson School of Medicine, Ariel University, Ariel, Israel

\section{Corresponding Author:}

Arriel Benis, PhD

Faculty of Industrial Engineering and Technology Management

Holon Institute of Technology

Golomb St. 52

Holon, 5810201

Israel

Phone: 97235026892

Email: $\underline{\text { arrielb@ hit.ac.il }}$

\begin{abstract}
Background: Vaccines are one of the most important achievements of modern medicine. However, their acceptance is only partial, with vaccine hesitancy and refusal representing a major health threat. Influenza vaccines have low compliance since repeated, annual vaccination is required. Influenza vaccines stimulate discussions both in the real world and online. Social media is currently a significant source of health and medical information. Elucidating the association between social media engagement and influenza vaccination is important and may be applicable to other vaccines, including ones against COVID-19.
\end{abstract}

Objective: The goal of this study is to characterize profiles of social media engagement regarding the influenza vaccine and their association with knowledge and compliance in order to support improvement of future web-associated vaccination campaigns.

Methods: A weblink to an online survey in Hebrew was disseminated over social media and messaging platforms. The survey answers were collected during April 2020. Anonymous and volunteer participants aged 21 years and over answered 30 questions related to sociodemographics; social media usage; influenza- and vaccine-related knowledge and behavior; health-related information searching, its reliability, and its influence; and COVID-19-related information searching. A univariate descriptive data analysis was performed, followed by multivariate analysis via building a decision tree to define the most important attributes associated with vaccination compliance.

Results: A total of 213 subjects responded to the survey, of whom 207 were included in the analysis; the majority of the respondents were female, were aged 21 to 40 years, had 1 to 2 children, lived in central Israel, were secular Israeli natives, had higher education, and had a salary close to the national average. Most respondents $(128 / 207,61.8 \%)$ were not vaccinated against influenza in 2019 and used social media. Participants that used social media were younger, secular, and living in high-density agglomerations and had lower influenza vaccination rates. The perceived influence and reliability of the information on social media about COVID-19 were generally similar to those perceptions about influenza.

Conclusions: Using social media is negatively linked to compliance with seasonal influenza vaccination in this study. A high proportion of noncompliant individuals can lead to increased consumption of health care services and can, therefore, overload these health services. This is particularly crucial with a concomitant outbreak, such as COVID-19. Health care professionals should use improved and targeted health communication campaigns with the aid of experts in social media. Targeted communication, based on sociodemographic factors and personalized social media usage, might increase influenza vaccination rates and compliance with other vaccines as well.

(J Med Internet Res 2021;23(3):e25977) doi: $\underline{10.2196 / 25977}$ 


\section{KEYWORDS}

influenza; vaccines; vaccination; social media; online social networking; health literacy; eHealth; information dissemination; access to information; COVID-19

\section{Introduction}

\section{Background}

Influenza is an acute, viral infectious disease characterized by high fever, cough, runny nose, muscle pain, joint pain, and severe exhaustion [1]. It is associated with multiple complications, including hepatitis, encephalitis, muscle tissue destruction, renal impairment, and secondary bacterial infection (ie, pneumonia, sinusitis, and, in children, middle ear infection) [2]. Although vaccines are one of the most important achievements of modern medicine, their acceptance among the population is only partial; this lack of compliance has been identified by the World Health Organization (WHO) as one of the major threats to public health. A wide variety of communication channels are now being used to improve worldwide vaccine responsiveness. There is a need to improve the efficacy of online communication, which is currently a significant source of health and medical information [3].

According to the WHO, every year around 1.5 billion people suffer from seasonal influenza, of whom 3 to 5 million have a serious illness, sometimes requiring hospitalization, and 650,000 die [1]. However, the percentage of the population who comply with seasonal vaccination against it is relatively low [4,5]. For example, in Israel, around $25 \%$ of the population are vaccinated against influenza each winter [6]. The second type of influenza relates to major changes in viral antigens occurring every few decades and, thus, leads to new influenza strains that are unfamiliar to the human immune system, causing a worldwide epidemic, called a pandemic, with tens of millions of sick patients and millions of deaths [1]. This occurred with the 1918 influenza pandemic, in which about one-third of the world's population was ill and 50 to 100 million people died [7-9].

Over the last decades, the internet has supported the monitoring, prediction, and surveillance (ie, infoveillance [10-12]) of epidemics and the behavior of the population, specifically in the context of influenza [13-15]. Furthermore, valuable information is discoverable, like early warnings of disease outbreaks, dissemination tracking, and resilience [16]. Social media and social networking services (SNSs) are powerful internet-based communication tools $[17,18]$. Each SNS has a variety of functionalities and goals. Facebook is a grand public-focused polyvalent platform. LinkedIn focuses on professional networking. Instagram, Flickr, and Pinterest deal with video and picture sharing. Twitter and Tumblr allow for blogging and microblogging. Reddit provides news aggregation, web content rating, and blogging services. Telegram is primarily used for instant and broadcast messaging to an unlimited number of subscribers over dedicated channels. Social media and SNSs, in particular, are also well known for disseminating evidence-based health care information and recommendations [14]. However, efficient and effective health-related information must be monitored and controlled for both quality and reliability [19], and confidentiality, privacy, and ethics of contacts between health care information customers and providers [20]. The social media impact must be understood in the field of health communication [21,22]. Accordingly, the development of relevant policies is needed $[23,24]$ for reducing the risk and impacts of the misinformation epidemic or the infodemic spread on media, and for building the appropriate capacities to support eHealth and science literacy $[25,26]$. There is a crucial need for public health decision makers who are concerned with disease literacy to give the health information providers appropriate tools for efficiently disseminating the information, taking into account possible personal and environmental influences [12].

Vaccination against influenza is a significant and cost-effective protective mechanism for reducing the disease burden related to its morbidity and mortality [5]. Nevertheless, at the population level, its coverage is insufficient due to factors influencing vaccination decisions and hesitancy, such as risk-benefit misperception or accessibility to the health care system [27]. A major contribution to these factors is communication, involving both social and mass media, family, friends, and health care professionals [28]. More specifically, social media could affect the compliance of the population to vaccination guidelines [27]. For example, those who advocate against vaccines use social media to disseminate their messages on a large scale, increasing vaccine hesitancy or refusal in the population [29].

Concerning the new COVID-19 vaccines, evaluating the relationship between the population's perception of and compliance with the vaccine against influenza is important. Therefore, this will contribute to creating effective means of online communication to improve vaccine acceptance [30-33].

\section{Aims and Objectives}

Social media and SNSs have been used to improve vaccine response worldwide. However, they are also a forum for vaccine opponents and spreading of fake news. Understanding social media engagement, influence, and reliability is a critical point for improving the efficacy of advertising and publicity policies on social media. Our primary aim is to support the design and the implementation of future eHealth strategies and interventions on social media to increase the quality of targeted communication campaigns and the influenza vaccination rates [6,34-36]. Our main objective is to describe and characterize profiles regarding influenza vaccination and their association with social media engagement, influence, and reliability. We specifically focus on the Israeli population in this study. The findings of this research may then support vaccination campaigns against COVID-19.

This cross-sectional survey-based research is led by three hypotheses:

1. The use of social media influences the vaccination compliance of health care customers.

2. Influenza vaccination compliance is affected by social factors and by perceptions, reliability, and influence of information from social media. 
3. The perceived influence and reliability of information from social media about SARS-CoV-2 or COVID-19 is similar to that regarding influenza.

Our goal is to identify sociodemographic and social media engagement attributes affecting influenza vaccination compliance. This research characterizes the differences between individuals vaccinated or not vaccinated against influenza during the 2019 season [37]. We attempt to understand whether there is a link between seasonal vaccination against influenza and social media engagement, influence, and perception of reliability during the COVID-19 pandemic.

This survey was granted ethical approval by the Ethics Committee of the Faculty of Technology Management of the Holon Institute of Technology (TM/2/2020/AB/002). The information provided by the participants during the survey are stored in a secured, encrypted manner, with restricted access provided by the institution of the principal researcher (AB).

\section{Methods}

\section{Overview}

We performed a cross-sectional survey of volunteers and anonymous Hebrew speakers over the internet about their online social network habits and their behavior concerning influenza vaccination. The survey was conducted over 14 days, between April 14 and 28, 2020, coinciding with the end of the seasonal influenza outbreak as well as the second month of the COVID-19 pandemic in Israel. Israel is a country in which a high percentage of the population uses the internet. With more than $80 \%$ of the population having at least one account on an SNS [38], it is among the highest in the world and is continuously increasing. Facebook is the leading social media platform used in Israel and the percentage of its users is continuously growing (eg, in April 2020: 62.87\%; in August 2020: $86.47 \%$ ) [39].

Upon consent, 213 participants were instructed to complete a 30-question survey asking about their usage and perception of health information available on social media, its reliability, and its influence on their compliance to vaccinate against influenza (see Multimedia Appendix 1) [40,41].

The survey was hosted on an Israeli website for the management of surveys in Hebrew-the IMKFORMS system-and its address was disseminated by publishing it on SNSs (ie, Facebook, Twitter, and LinkedIn) and instant messaging platforms (ie, WhatsApp and Telegram) and by sending its link via email to personal and professional contact lists.

The questionnaire included five subsets of questions, each with a specific focus:

1. Sociodemographics (9 questions), including gender, age range, relationship status, number of children, area of residence, country of birth, religious affiliation, education, and monthly income.

2. Social media usage (2 questions), including the self-estimated daily amount of social media use and the types of involvement on different social media platforms.
3. Influenza and vaccine-related knowledge and behavior (5 questions), including vaccine status in 2019, knowledge about the influenza vaccine, reasons for taking the seasonal influenza vaccine, and chronic disease in the family.

4. Health-related information searching and publishing, its reliability, and its influence (9 questions), including confidence in sources of information and searching for information, reliability and influence, and types and intensity of involvement on different social media platforms regarding health, vaccines, and influenza.

5. COVID-19- and vaccine-related information searching and publishing, its reliability, and its influence (5 questions), including sources and searching for information, reliability and influence, and types and intensity of involvement on different social media platforms regarding the COVID-19 pandemic.

The questions dealing with social media usage, reliability, and influence were in the form of matrix point rating multiple-choice questions with 4-point Likert scales.

\section{Data Analysis}

By using the exclusion criteria, we removed the full answer sets of responders who declared residence outside Israel or who did not answer at least one of the sociodemographic questions. We redefined some categories to facilitate the data analysis by working with groups comprising, as much as possible, the largest number of similar answers (eg, age groups, relationship status, number of children, area of residence, country of birth, education, and social media activity, reliability, and influence). Descriptive statistics such as frequencies and proportions were computed. Chi-square tests and Fisher exact tests were used to compare categorical variables. Cronbach $\alpha$ was used to measure the internal reliability of social media usage, reliability, and influence (Cronbach $\alpha=.949$ ). The categorical variables were presented as numbers and percentages. Statistical significance was considered with a 2 -sided $P$ value of .05 or less. However, the borderline values have not been considered as not being significant in the evaluation [42]. To promote the effective focusing of communication to encourage vaccination against influenza, a set of factors were considered. Building a decision tree allowed, in this case, the definition of target profiles and the overcoming of Simpson's paradox, which may limit the quality of the decision support provided to decision makers. This phenomenon describes situations in which a trend appears in some groups of data but disappears when these groups are aggregated and vice versa [43]. Therefore, these learning classifiers allow nonlinear interactions between attributes and are easily interpretable. The decision tree for predicting vaccinated and unvaccinated profiles [44] was built by considering attributes with $P \leq .10$ that were used in further multivariate analysis.

The data analysis was performed with $\mathrm{R}$, version 4.0.2 (The $\mathrm{R}$ Foundation). The psych package [45] was used for computing the internal consistency of reliability of the answers to the matrix multipoint scale questions. The compareGroups package [46] was used for statistical computations. The rpart package [47] was used for the decision tree processing [48]. 
The manuscript adheres to reporting standards, including the Checklist for Reporting Results of Internet E-Surveys (CHERRIES) and the Strengthening the Reporting of Observational Studies in Epidemiology (STROBE) guidelines [49-51].

\section{Results}

\section{Study Population}

\section{Overview}

The population of survey participants (see Table 1) includes 207 individuals after applying the exclusion criteria on 213 total responders. A substantial proportion of the participants were female $(126 / 207,60.9 \%)$, between the ages of 21 and 40 years $(47 / 207,71.0 \%)$, in a relationship $(156 / 207,75.4 \%)$, with 1 to 2 children (101/207, 48.8\%), and living in central Israel $(130 / 207,62.8 \%)$. Additionally, the majority of survey participants were Israeli natives $(116 / 207,56.0 \%)$, had a secular affiliation (144/207, 69.6\%), possessed higher education $(182 / 207,87.9 \%)$, and had a salary near the national average $(81 / 207,39.1 \%)$, which is around 12,000 New Israeli Shekels per month (US \$3092.78) [52]. Regarding demography of social media usage and vaccination status, the majority of respondents were not vaccinated against influenza in 2019 (128/207, 61.8\%) and used social media $(119 / 207,57.5 \%)$. 
Table 1. Sociodemographic characteristics of the survey population.

\begin{tabular}{|c|c|c|c|c|c|c|c|}
\hline \multirow[t]{2}{*}{ Characteristic } & \multirow{2}{*}{$\begin{array}{l}\text { All participants } \\
(\mathrm{N}=207), \mathrm{n}(\%)\end{array}$} & \multicolumn{3}{|c|}{ Social media user } & \multicolumn{3}{|c|}{ Vaccinated in 2019} \\
\hline & & $\begin{array}{l}\text { Yes }(\mathrm{n}=119) \\
\mathrm{n}(\%)\end{array}$ & $\begin{array}{l}\text { No }(\mathrm{n}=88), \mathrm{n} \\
(\%)\end{array}$ & $P$ value & $\begin{array}{l}\text { Yes }(\mathrm{n}=79), \mathrm{n} \\
(\%)\end{array}$ & $\begin{array}{l}\text { No }(\mathrm{n}=128), \mathrm{n} \\
(\%)\end{array}$ & $P$ value \\
\hline Vaccinated in 2019 & & & & $<.001$ & & & $\mathrm{~N} / \mathrm{A}^{\mathrm{a}}$ \\
\hline Yes & $79(38.2)$ & $31(26.1)$ & $48(55)$ & $-{ }^{b}$ & N/A & N/A & N/A \\
\hline No & $128(61.8)$ & $88(73.9)$ & $40(45)$ & - & N/A & N/A & N/A \\
\hline Social media user & & & & N/A & & & $<.001$ \\
\hline Yes & $119(57.5)$ & N/A & N/A & N/A & $31(39)$ & $88(68.8)$ & - \\
\hline No & $88(42.5)$ & N/A & N/A & N/A & $48(61)$ & $40(31.2)$ & - \\
\hline Gender & & & & .07 & & & .11 \\
\hline Male & $81(39.1)$ & $53(44.5)$ & $28(32)$ & - & $25(32)$ & $56(43.8)$ & - \\
\hline Female & $126(60.9)$ & $66(55.5)$ & $60(68)$ & - & $54(68)$ & $72(56.2)$ & - \\
\hline Age category (years) & & & & .002 & & & .11 \\
\hline $21-30$ & $48(23.2)$ & $34(28.6)$ & $14(16)$ & - & $12(15)$ & $36(28.1)$ & - \\
\hline $31-40$ & $99(47.8)$ & $63(52.9)$ & $36(41)$ & - & $41(52)$ & $58(45.3)$ & - \\
\hline $41-50$ & $38(18.4)$ & $14(11.8)$ & $24(27)$ & - & $15(19)$ & $23(18.0)$ & - \\
\hline $51-60$ & $15(7.2)$ & $7(5.9)$ & $8(9)$ & - & $6(8)$ & $9(7.0)$ & - \\
\hline$\geq 61$ & $7(3.4)$ & $1(0.8)$ & $6(7)$ & - & $5(6)$ & $2(1.6)$ & - \\
\hline Relationship status & & & & .04 & & & .008 \\
\hline Not in a relationship & $51(24.6)$ & $36(30.3)$ & $15(17)$ & - & $11(14)$ & $40(31.2)$ & - \\
\hline In a relationship & $156(75.4)$ & $83(69.7)$ & $73(83)$ & - & $68(86)$ & $88(68.8)$ & - \\
\hline No. of children & & & & .009 & & & .03 \\
\hline 0 & $58(28.0)$ & $43(36.1)$ & $15(17)$ & - & $14(18)$ & $44(34.4)$ & - \\
\hline $1-2$ & $101(48.8)$ & $53(44.5)$ & $48(55)$ & - & $45(57)$ & $56(43.8)$ & - \\
\hline $3-6$ & $48(23.2)$ & $23(19.3)$ & $25(28)$ & - & $20(25)$ & $28(21.9)$ & - \\
\hline Residence & & & & .02 & & & .53 \\
\hline Center & $130(62.8)$ & $66(55.5)$ & $64(73)$ & - & $47(59)$ & $83(64.8)$ & - \\
\hline Periphery & $77(37.2)$ & $53(44.5)$ & $24(27)$ & - & $32(41)$ & $45(35.2)$ & - \\
\hline Country of birth & & & & .002 & & & .82 \\
\hline Israel & $116(56.0)$ & $55(46.2)$ & $61(69)$ & - & $43(54)$ & $73(57.0)$ & - \\
\hline Aboard & $91(44.0)$ & $64(53.8)$ & $27(31)$ & - & $36(46)$ & $55(43.0)$ & - \\
\hline Religious affiliation & & & & .21 & & & .03 \\
\hline Secular & $144(69.6)$ & $89(74.8)$ & $55(63)$ & - & $50(63)$ & $94(73.4)$ & - \\
\hline Traditional & $40(19.3)$ & $19(16.0)$ & $21(24)$ & - & $15(19)$ & $25(19.5)$ & - \\
\hline Religious & $17(8.2)$ & $7(5.9)$ & $10(11)$ & - & $12(15)$ & $5(3.9)$ & - \\
\hline Other & $6(2.9)$ & $4(3.4)$ & $2(2)$ & - & $2(3)$ & $4(3.1)$ & - \\
\hline Education (years) & & & & .71 & & & .99 \\
\hline$\leq 12$ & $25(12.1)$ & $13(10.9)$ & $12(14)$ & - & $9(11)$ & $16(12.5)$ & - \\
\hline$>12$ & $182(87.9)$ & $106(89.1)$ & $76(86)$ & - & $70(89)$ & $112(87.5)$ & - \\
\hline Monthly gross income (NIS ${ }^{c}$ ) & & & & .28 & & & .75 \\
\hline $5001-10,000$ & $33(15.9)$ & $24(20.2)$ & $9(10)$ & - & $10(13)$ & $23(18.0)$ & - \\
\hline $10,001-20,000$ & $81(39.1)$ & $42(35.3)$ & $39(44)$ & - & $35(44)$ & $46(35.9)$ & - \\
\hline
\end{tabular}




\begin{tabular}{|c|c|c|c|c|c|c|c|}
\hline \multirow[t]{2}{*}{ Characteristic } & \multirow{2}{*}{$\begin{array}{l}\text { All participants } \\
(\mathrm{N}=207), \mathrm{n}(\%)\end{array}$} & \multicolumn{3}{|c|}{ Social media user } & \multicolumn{3}{|c|}{ Vaccinated in 2019} \\
\hline & & $\begin{array}{l}\text { Yes }(\mathrm{n}=119) \\
\mathrm{n}(\%)\end{array}$ & $\begin{array}{l}\text { No }(\mathrm{n}=88), \mathrm{n} \\
(\%)\end{array}$ & $P$ value & $\begin{array}{l}\text { Yes }(n=79), n \\
(\%)\end{array}$ & $\begin{array}{l}\text { No }(\mathrm{n}=128), \mathrm{n} \\
(\%)\end{array}$ & $P$ value \\
\hline $20,001-25,000$ & $28(13.5)$ & $16(13.4)$ & $12(14)$ & - & $9(11)$ & $19(14.8)$ & - \\
\hline $25,001-30,000$ & $20(9.7)$ & $14(11.8)$ & $6(7)$ & - & $7(9)$ & $13(10.2)$ & - \\
\hline$\geq 30,001$ & $25(12.1)$ & $13(10.9)$ & $12(14)$ & - & $9(11)$ & $16(12.5)$ & - \\
\hline Did not disclose & $20(9.7)$ & $10(8.4)$ & $10(11)$ & - & $9(11)$ & $11(8.6)$ & - \\
\hline $\begin{array}{l}\text { Do you or a family member } \\
\text { have a chronic disease? }\end{array}$ & & & & .90 & & & .45 \\
\hline Yes & $94(45.4)$ & $55(46.2)$ & $39(44)$ & - & $39(49)$ & $55(43.0)$ & - \\
\hline No & $113(54.6)$ & $64(53.8)$ & $49(56)$ & - & $40(51)$ & $73(57.0)$ & - \\
\hline
\end{tabular}

${ }^{\mathrm{a}} \mathrm{N} / \mathrm{A}$ : not applicable; irrelevant test.

${ }^{\mathrm{b}} P$ values were calculated for categories and not for individual subcategories.

${ }^{\mathrm{c}}$ NIS: New Israeli Shekel; the currency exchange rate at the time of publication was US \$1 for NIS 3.88.

${ }^{\mathrm{d}} \mathrm{Up}$ to a second degree.

\section{Social Media Users}

There were significantly fewer social media users vaccinated against influenza in $2019(31 / 109,26.1 \% ; P<.001)$ compared to nonusers $(48 / 88,55 \%)$. In both groups, the responders were predominantly female (users: $66 / 119,55.5 \%$ vs nonusers: $60 / 88$, $68 \% ; P=.09)$ and in a relationship $(83 / 119,69.7 \%$ vs $73 / 88$, $83 \% ; P=.04)$. However, the social media users were globally younger, 21 to 40 years old $(97 / 119,81.5 \%$ vs $50 / 88,67 \%)$, whereas the nonusers were older, aged between 31 and 60 years $(68 / 88,77 \%)$. Similarly, the former group often had no children $(36 / 118,80.6 \%)$, whereas the nonusers had children in most cases $(73 / 88,83 \%)$. Still, most respondents lived in central Israel $(66 / 119,55.5 \%$ and $64 / 88,73 \%)$, but residents of the periphery used significantly more social media than those living in the center $(53 / 119,44.5 \%$ vs $24 / 88,27 \% ; P=.02)$. Additionally, in the survey population, Israeli natives used social media significantly less than immigrants $(55 / 119,46.2 \%$ vs $64 / 119$, 53.8\%; $P=.002)$.

Furthermore, the proportion of people of traditional or religious affiliation who did not use social media was higher than their proportion in the group of users $(31 / 88,35 \%$ vs $26 / 119,21.8 \%$; $P=.21$ ). The level of education, declared monthly gross income, and experience of chronic disease by themselves or by a family member did not appear to be a determinant of overall social media use ( $P=.28, P=.71$, and $P=.90$, respectively).

\section{Vaccinated Versus Unvaccinated in 2019}

The percentage of respondents vaccinated against influenza in 2019 was significantly $(P<.001)$ higher in the group of social media nonusers than in the users' group $(48 / 79,61 \%$ vs $31 / 79$, $39 \%)$; inversely, the percentage of unvaccinated respondents was higher in the group of social media users $(88 / 128,68.8 \%$ vs $40 / 128,31.2 \%)$. Furthermore, the proportion of vaccinated people was higher when the responders were in a relationship $(68 / 79,86 \%$ vs $88 / 128,68.8 \% ; P=.008)$ and had children $(65 / 79$, $83 \%$ vs $84 / 128,65.7 \% ; P=.03)$. The degree of religious affiliation provided critical insight into this study. The secular participants in the survey represented a higher proportion of unvaccinated people (unvaccinated: 94/128, $73.4 \%$ vs vaccinated: 50/79, 63\%), while those with religious affiliations were more compliant (unvaccinated: $5 / 128,3.9 \%$ vs vaccinated: $12 / 79,15 \%)$. Similar to the use of social media, influenza vaccination was not associated with chronic disease, personally or among family members $(P=.45)$.

\section{Social Media Usage and Vaccination Status}

The participants in the survey were asked to specify which social media platforms they used actively (ie, publishing or reacting to posts), passively (ie, reading posts), or not at all (see Figure 1 and Multimedia Appendix 2). The participants declared using Facebook (115/207, 55.0\%), Instagram (81/207, 39.1\%), LinkedIn (60/207, 28.9\%), Telegram (36/207, 17.4\%), and others (ie, Twitter, Tumblr, Reddit, Flickr, and other social media platforms) as a whole $(38 / 207,18.4 \%)$. More accurately, Facebook, Instagram, and Telegram users were significantly $(P=.001)$ less vaccinated in 2019. The use of LinkedIn or other unspecified social media platforms was not significantly associated with vaccination status $(P=.30$ and $P=.14$, respectively). 
Figure 1. Social media usage and vaccination status against influenza in 2019.

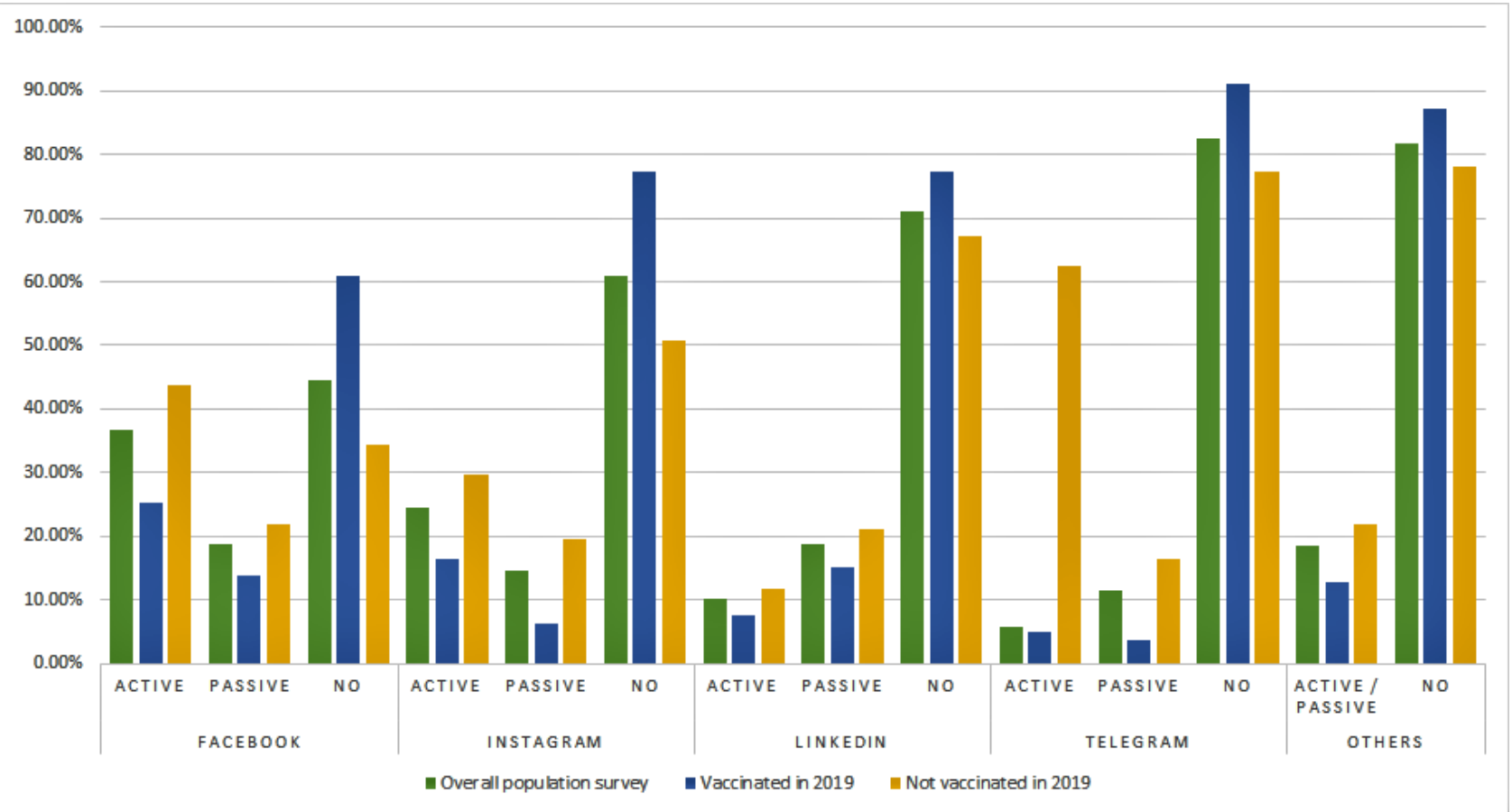

Moreover, no significant difference was observed between the groups regarding the belief that the vaccine against influenza caused the disease (between $62.0 \%$ and $68.0 \% ; P>.47$ ), nonetheless a majority of participants knew that the influenza vaccine is an attenuated or inactivated virus $(150 / 207,72.5 \%)$.

\section{Reasons for Receiving the Influenza Vaccine in 2019}

The reasons for receiving the annual influenza vaccine varied from one individual to another (see Figure 2 and Multimedia Appendix 3). The participants vaccinated in 2019 (79/207, $38.2 \%)$ were divided into social media users $(31 / 79,39 \%)$ and nonusers of social media $(48 / 79,61 \%)$. The proportion of yearly vaccinated individuals was similar in both groups $(14 / 31,45 \%$ vs $23 / 48,48 \%$ ). Receiving a reminder from a health maintenance organization (HMO) seemed to significantly influence the compliance with vaccination for the group of individuals who were not vaccinated annually $(6 / 7,86 \% ; P=.09$ vs $9 / 11,82 \%$; $P=.06)$. Among those who have discussed the issue with relatives, seen advertisements in the media, or gotten information via social media, some differences were noticeable. The social media users seeing advertisements may have been influenced by these communication tools and took the vaccine in 2019 in contrast to previous years $(4 / 9,44 \%)$. A relatively high proportion $(14 / 79,18 \%)$ of individuals were vaccinated in 2019 but had not been vaccinated annually. This may be associated with the COVID-19 pandemic and the worry that it induced [53]. Moreover, a majority of the responders who were not vaccinated yearly received the vaccine after a discussion with relatives when they were not social media users $(7 / 8,88 \%$ vs $3 / 6,50 \%$; odds ratio $7.0,95 \%$ CI $0.50-97.75 ; P=.15)$.

Figure 2. Reasons for receiving the influenza vaccine in 2019. The plot shows all participants and stratification by social media use and vaccination against influenza in 2019. HMO: health maintenance organization.

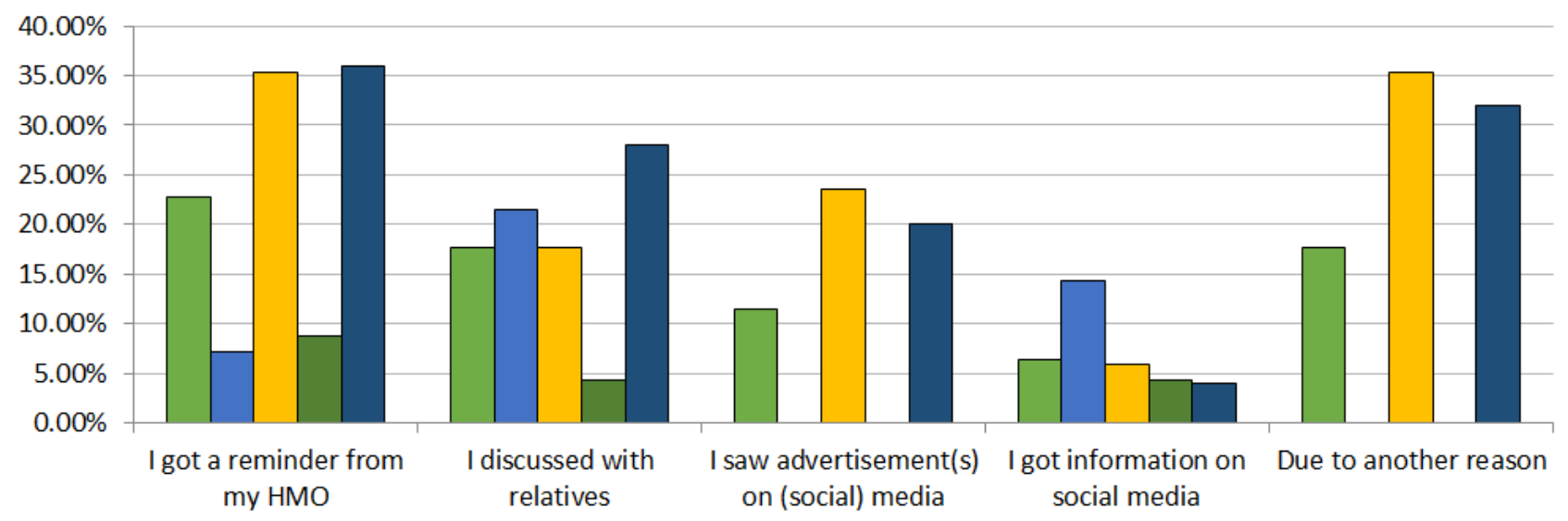

$\square$ Overall

$\square$ Social media user not vaccinated yearly

$\square$ Non-social media user not vaccinated yearly $\square$ Social media user vaccinated yearly

$\square$ Non-social media user vaccinated yearly 


\section{Searching for and Publishing Information Related to Health, Specifically to Influenza Vaccines}

Social media is the main source of information and news consumption [54,55]. Anyone can post content and thus publish "information" (see Multimedia Appendix 4). No significant differences were observed in health information-related searches, influenza vaccine-related posting, and COVID-19-related posting $(P>.30)$. However, declared behavior was significantly associated with vaccination against influenza and with the search for influenza vaccine- and COVID-19-related information $(22 / 79,28 \%$ vs $11 / 128,8.6 \%$; $P<.001$, and $26 / 79,33 \%$ vs $23 / 128,18.0 \% ; P=.02$, respectively), as well as publishing of health-related information $(46 / 79,58 \%$ vs $56 / 128,43.8 \% ; P=.06)$. These results show that vaccinated individuals were more active and involved in their health management by searching for and sharing relevant information.

\section{Reliability, Influence, and Confidence Perceptions of Influenza-, Vaccine-, and COVID-19-Related Information on Social Media Platforms}

The survey participants were asked to report their perceptions of reliability, influence, and confidence of influenza-, vaccine-, and COVID-19-related information available on the social media platforms (see Multimedia Appendices 5 and 6). The proportion of participants with no opinion was relatively high (at least $118 / 207,57.0 \%$ ) and higher than that in the social media nonusers group $(88 / 207,42.5 \%)$. The no opinion answer was not considered as a full lack of positioning but rather as a lack of use, knowledge, or understanding of a platform. It seems that the social media users were not aware of the impacts of these platforms on their behaviors. Facebook received the highest score of reliability $(71 / 207,34.3 \% ; P=.06$ and 74/207, 35.7\%; $P=.003)$ and the score was higher in the nonvaccinated group $(50 / 128,39.1 \%)$. The influence of the information about the influenza vaccine was not considered as being substantial (53/207, 25.6\%). For COVID-19, the results were different: two-thirds of the participants, not vaccinated and having an opinion, were influenced by the information appearing on social media.

The users' trust in the source of information is crucial. The majority of participants had confidence in governmental and health organizations (overall: 155/207, 74.9\%; vaccinated: $65 / 79,82 \%$; nonvaccinated: $38 / 128,29.7 \%$ ). Interestingly, the participants generally had less confidence in health care professionals as a source of influenza vaccine-related information (overall: 84/207, 40.6\%; vaccinated: $39 / 79,49 \%$; nonvaccinated: $45 / 128,35.2 \% ; P=.06)$. These two sources represent those with the highest levels of trust and, as such, the highest levels of influence. One-third of the participants were confident in scientific publications (70/207, 33.8\%). Moreover, the information provided by relatives had some credibility $(17 / 207,8.2 \%)$. The pharmaceutical industry and the vaccine opponents' information were strongly rejected $(>97.6 \%)$.

\section{Multivariate Analysis}

The multivariate analysis consisted of building decision trees enabling the classification of individuals to be vaccinated or unvaccinated against influenza and so defining target profiles for increasing vaccination engagement. As presented in the univariate analysis (Multimedia Appendices 2-7), multiple decision trees were built with the subsets of attributes (see Multimedia Appendix 8) without considering the $P$ values, with and without using the COVID-19-related set. The decision trees were built using a training data set of $66.2 \%$ (137/207) randomly selected records and their prediction capabilities were tested on the rest $(70 / 207,33.8 \%)$.

One decision tree was built with all attributes with $P \leq .10$ and with the exclusion of the COVID-19-related attributes (56/70, $80 \%$ of the test samples were rightly classified as vaccinated or not). The root of this decision tree was due to another reason as the reason given for being vaccinated in the 2019 season. In the overall survey, this represented $18 \%$ (14/79) of the vaccinated individuals or $6.8 \%$ of the responders (14/207). Moreover, the same group reported that they were not vaccinated annually (see Multimedia Appendix 3). To build a decision tree that supports efficient decision making by the domain expert, this attribute did not allow the targeting of a specific subpopulation. Hence, the increase in the number of people vaccinated may be due to fear of the pandemic [53] and the popular misunderstanding of the differences between seasonal influenza and SARS-CoV-2 (ie, the COVID-19 pandemic) [33].

Consequently, two decision trees were built without the due to another reason attribute: the first was built on all attributes with $P \leq .10$, and the second further excluded the COVID-19-related attributes as inputs. The same decision tree was generated (see Figure 3), with an overall performance of $76 \%$ (53/70 of the test sample were rightly classified as vaccinated or not). The difference in the classification performances of the trees with the declaration due to another reason or without it was $4 \%$ $(3 / 70)$. This means that the majority $(11 / 14,79 \%)$ of the individuals vaccinated for this reason were rightly classified even without taking it into account. 
Figure 3. Decision tree predicting vaccinated individuals based on all survey attributes with $P \leq .10$ and without the due to another reason attribute. HMO: health maintenance organization.

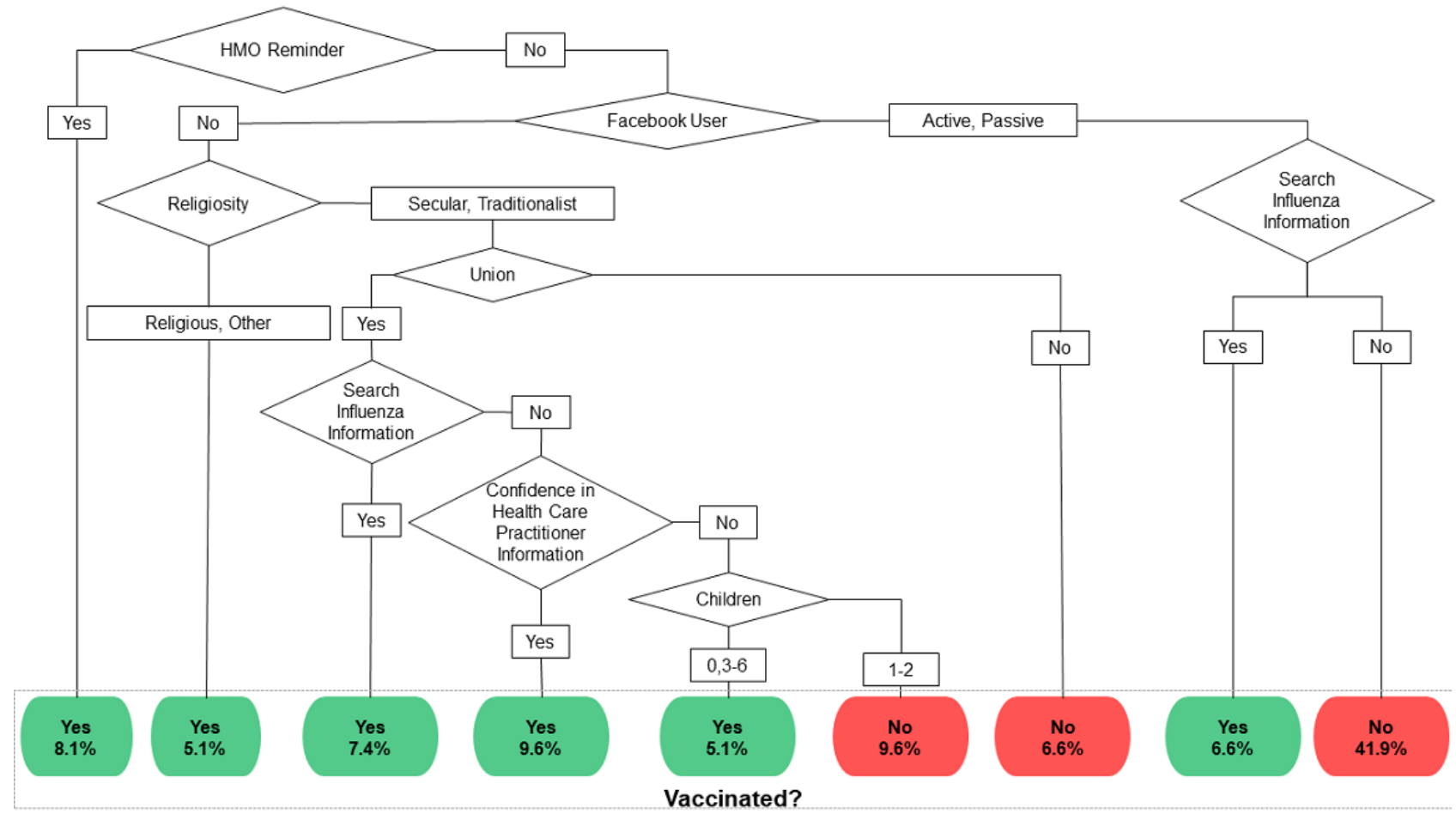

Not focusing particularly on COVID-19 did not have an impact on classification. This supports our main objective, which was to characterize profiles of vaccination engagement in a simple and generalizable way.

The root of the proposed decision tree (see Figure 3) was a reason for obtaining the seasonal vaccine and it was a nonsocial attribute: I got a reminder from my HMO (11/137, 8.1\% of the training set; $P=.08)$. This reminder was sent by HMOs via SMS and the majority of those who received it were compliant and vaccinated (see Figure 3 and Multimedia Appendix 4).

The next node involved discrimination between Facebook users and nonusers (node Facebook User). The group of individuals engaged with this social media platform were less vaccinated than its nonusers. However, they actively searched for information related to influenza vaccines (ie, Search Influenza Information); thus, their health literacy seemed to positively influence vaccination compliance $(9 / 70,7 \% ; P=.07)$.

On the other hand, the Facebook nonusers were then split by their religious practice (ie, Religiosity). The individuals who were not vaccinated because they did not receive an HMO reminder and were also not users of Facebook were, for the majority, vaccinated if they were religious or had another level of practice, meaning neither secular nor traditional $(7 / 137$, $5.1 \% ; P=.05)$. In the last node, those not in a relationship were more likely not to be vaccinated $(9 / 137,6.6 \% ; P=.07)$.

The majority of those who identified as secular or traditional, were in a relationship, and searched for influenza vaccine information were also vaccinated $(10 / 137,7.4 \% ; P=.07)$. Those who did not search for information but were confident in the information provided by health care practitioners also showed good compliance $(13 / 137,9.6 \%$; $P=.10)$. Surprisingly, those who were not confident, and who had no children or more than
3 children, were often vaccinated $(7 / 137,5.1 \% ; P=.05)$, while parents of 1 or 2 children were less often vaccinated (13/137, $9.6 \% ; P=.10)$.

\section{Discussion}

\section{Principal Findings}

This study aimed to quantify the contribution of social media and its perceived reliability to modern health care customer behavior, thus highlighting the centrality of these media platforms to influence treatment and, specifically, compliance with influenza vaccination [56,57]. The most important outcome of this study is building a decision tree that is based on our findings and supports a multivariate and integrative viewpoint. It is actually reasonable that various interacting links exist between the seasonal vaccination against influenza and social media engagement, influence, and reliability in Israel during the COVID-19 pandemic [39]. Indeed, being or not being a user of social media or searching for information about the influenza vaccine present strong associations with vaccination status. Nevertheless, the vaccination reminders sent by the HMO are one of the most crucial factors in vaccination compliance.

The results show that the use of social media influences vaccination compliance in the Israeli population. This is correlated with sociodemographic factors and with perceptions of influence and reliability of information from social media. Indeed, social media users were less frequently vaccinated than nonusers. More accurately, this group was composed of younger people with secular affiliations living in the center of the country (ie, high-density agglomeration) and were less vaccinated.

According to the data collected during the survey, social media is largely used in Israel by young (ie, <40 years old), urban (ie, specifically, living in densely populated central Israel), and 
more highly educated people. This research highlights that social media users and the majority of the nonvaccinated population are the younger population who also acknowledge their confidence in the reliability and influence of social media, concurrent with their low confidence in the information disseminated by governmental and health organizations and health professionals.

The perceived influence and reliability of the information on social media about COVID-19 are similar, in general, to those perceptions of the information about influenza. Accordingly, the risk of nonadherence to recommendations by governmental and health organizations to reduce the spread of these pandemic viruses (ie, hygiene measures, distancing, and vaccination) may be similar. Notably, while both parameters are relatively significant, the nonvaccinated subpopulation searches for information regarding influenza vaccination substantially less than information regarding SARS-CoV-2 or COVID-19. Social media platforms were used during the survey period by local, national, and international agencies (ie, governmental and health care organizations) to provide up-to-date facts, guidance, and directives to the public [58]. With this in mind, and considering the 2019-2020 influenza season time frame [37], 6.8\% (14/207) of the respondents sought out the influenza vaccine, deviating from their habits.

\section{Strengths and Limitations}

A major limitation of this study is that it was based on an online survey written in Hebrew and disseminated over the internet via social media, primarily to Israeli residents. This method limited the type of individuals who responded to the survey and the generalization of the results. Moreover, even though about half of the survey responders were not Israeli natives, the Hebrew language of the survey rendered it inaccessible to nonfluent Hebrew speakers (eg, new immigrants, residents who have not learned the language, and non-Hebrew speakers of the Arab sector). Furthermore, as the survey was disseminated over the internet, particularly by publication on social networks, it did not include representation of the ultra-Orthodox sector, which represents around $12 \%$ of the Israeli population. It is, therefore, suggested that similar studies be performed in other locations and using diverse languages. Still, Israel is recognized as one of the countries with high, and continuously increasing, penetration of internet and social media [38,39].

Regarding the strengths of the study, the seasonal influenza outbreaks and pandemics with the need for repeated vaccinations are an excellent model for understanding the behavior of the population, its risk perception [59], its fear [60], and the consequences of information fatigue [61]. Social media supports the dissemination of a constant flow of information from numerous sources. In the context of influenza and COVID-19, these sources are institutional and professional news channels, in parallel with mass populations who can easily share their opinions and information over any social media platform. Crisis-related communication uses social media to "communicate, self-organize, manage, and mitigate risks" and "make sense of the event" [62] in a rapid manner and on influential channels [63].
Indeed, social media and the internet, in general, are defined as common sources of information on measles and its vaccine. Similar to the findings of this study, use of social media is also associated with erroneous knowledge and noncompliance with vaccination recommendations against measles [64].

Health communication countermeasures must be developed to increase the efficiency of campaigns for vaccination [64]. They must be dynamically adapted over all the communication channels in order to increase engagement for influenza and other vaccines, thereby reducing the potential additional overload on health care organizations $[65,66]$.

\section{Conclusions}

Social media is currently a leading and user-centered source of health information. The information available about influenza and the vaccines against it appears reliable and influences its readers, and this is significantly correlated with seasonal influenza vaccination compliance. Accordingly, it is crucial to improve the targeting of health communication campaigns in social media in order to increase compliance.

A high proportion of noncompliant and, therefore, nonvaccinated individuals can lead to increased consumption of health care services and an overload of the system. Therefore, in the COVID-19 era, and similarly to other epidemics and pandemics, health care services are overwhelmed by an excess of sick patients. Consequently, efficient communication actions with the individual, familial, and societal spheres; education on the benefits of vaccination; and education on the risks associated with infection are essential.

A future intervention must be efficiently implemented by developing new health communication processes, considering vaccinated and nonvaccinated individual profiles defined in a periodically updated way by building, for example, specific decision trees as proposed in this research (see Figure 3). This must be based on improving the health communication flow on social media, in near-real time, by monitoring and adapting targeted campaigns for facing rapid information changes in the internet sphere (eg, breaking news and fake news) [67].

Furthermore, most of the participants in this research were young. Nowadays, social media and social networks are used across the population regardless of, for example, age, gender, relationship status, education, religious affiliation, and country of residence. Consequently, social media-based health communication aiming to increase treatment compliance and, more accurately herein, influenza vaccination must take into account sociodemographic variables at a local level for efficiently and effectively targeting individuals to be motivated to vaccinate. This means delivering information to social media users in language that is easy to understand, in the languages spoken by various native and immigrant communities in the country, to ensure that the information reaches all residents. Additionally, the use of reminders, similar to those on SMS, should be generalized to social media by utilizing tailored advertisements [68,69]. 


\section{Acknowledgments}

The research of AB, EL, and SA is supported by a grant from Ariel University and Holon Institute of Technology, Israel: Applications of Artificial Intelligence for Enhancing the Efficiency of Vaccination Programs (No. RA19000000649).

\section{Authors' Contributions}

All authors attest that they meet the International Committee of Medical Journal Editors criteria for authorship, have reviewed the version of the manuscript to be submitted, and agreed with its content and submission. AB was responsible for the conception, design, and conduct of the study; data analysis; preparation and submission of documentation to the Ethics Committee; data interpretation; writing of the first draft of the manuscript; and critical review and revision of the manuscript for important intellectual content. AN and SR were responsible for the conception and design of the study, data collection, data analysis, data interpretation; writing of the first draft of the manuscript; and critical review and revision of the manuscript for important intellectual content. AN and SR are students of the Master of Science of Technology Management, Holon Institute of Technology, Israel (under the supervision of $\mathrm{AB}$ ). EL was responsible for data analysis, data interpretation, and critical review and revision of the manuscript for important intellectual content. SA was responsible for the conception and design of the study, data analysis, data interpretation, and critical review and revision of the manuscript for important intellectual content.

\section{Conflicts of Interest}

None declared.

\section{Multimedia Appendix 1}

Questionnaire on the behavior of social media users regarding health and vaccine issues.

[PDF File (Adobe PDF File), $81 \mathrm{~KB}-$ Multimedia Appendix 1]

\section{Multimedia Appendix 2}

Social media general usage and vaccination status against influenza in 2019.

[PDF File (Adobe PDF File), 62 KB-Multimedia Appendix 2]

\section{Multimedia Appendix 3}

Reasons for obtaining the influenza vaccine in 2019. The plot shows all participants and stratification by social media use and vaccination against influenza in 2019.

[PDF File (Adobe PDF File), 59 KB-Multimedia Appendix 3]

\section{Multimedia Appendix 4}

Searching for and publishing information related to health and specifically to influenza vaccines and COVID-19 in the 12 months before participating in the survey.

[PDF File (Adobe PDF File), 59 KB-Multimedia Appendix 4]

\section{Multimedia Appendix 5}

Perception of reliability and influence of the information related to influenza and vaccine and COVID-19 available on the most used social media platforms.

[PDF File (Adobe PDF File), 73 KB-Multimedia Appendix 5]

\section{Multimedia Appendix 6}

Perception of reliability and influence of the information related to influenza and vaccine and COVID-19 available on the most used social media platforms between social media users and social media nonusers.

[PDF File (Adobe PDF File), 64 KB-Multimedia Appendix 6]

\section{Multimedia Appendix 7}

Confidence in sources of information about the vaccine against influenza.

[PDF File (Adobe PDF File), $51 \mathrm{~KB}-$ Multimedia Appendix 7]

\section{Multimedia Appendix 8}

Prediction capabilities of decision trees based on the survey data. 


\section{References}

1. Influenza (Seasonal). World Health Organization. 2018 Nov 06. URL: https://www.who.int/en/news-room/fact-sheets/ detail/influenza-(seasonal) [accessed 2021-03-09]

2. Rothberg MB, Haessler SD. Complications of seasonal and pandemic influenza. Crit Care Med 2010 Apr;38(4 Suppl):e91-e97 [FREE Full text] [doi: 10.1097/CCM.0b013e3181c92eeb] [Medline: 19935413]

3. Rivas H, Wac K, editors. Digital Health: Scaling Healthcare to the World. Cham, Switzerland: Springer International Publishing; 2018.

4. Marshall GS. The Vaccine Handbook: A Practical Guide for Clinicians. 3rd edition. West Islip, NY: Professional Communications, Inc; 2010.

5. Fine P, Eames K, Heymann DL. "Herd immunity": A rough guide. Clin Infect Dis 2011 Apr 01;52(7):911-916 [FREE Full text] [doi: 10.1093/cid/cir007] [Medline: 21427399]

6. Feemster KA. Building vaccine acceptance through communication and advocacy. Hum Vaccin Immunother 2020 May 03;16(5):1004-1006. [doi: 10.1080/21645515.2020.1746603] [Medline: 32401681]

7. Taubenberger JK, Morens DM. 1918 influenza: The mother of all pandemics. Emerg Infect Dis 2006 Jan;12(1):15-22 [FREE Full text] [doi: 10.3201/eid1201.050979] [Medline: 16494711]

8. Potter CW. A history of influenza. J Appl Microbiol 2001 Oct;91(4):572-579 [FREE Full text] [doi: 10.1046/j.1365-2672.2001.01492.x] [Medline: 11576290 ]

9. Quinn T. Flu: A Social History of Influenza. London, UK: New Holland Publishers; 2008.

10. Eysenbach G. What is e-health? J Med Internet Res 2001;3(2):e20 [FREE Full text] [doi: 10.2196/jmir.3.2.e20] [Medline: 11720962]

11. Eysenbach G. Infodemiology: The epidemiology of (mis)information. Am J Med 2002 Dec 15;113(9):763-765 [FREE Full text] [doi: $10.1016 / \mathrm{s} 0002-9343(02) 01473-0]$ [Medline: 12517369$]$

12. Eysenbach G. Infodemiology and infoveillance: Tracking online health information and cyberbehavior for public health. Am J Prev Med 2011 May;40(5 Suppl 2):S154-S158 [FREE Full text] [doi: 10.1016/j.amepre.2011.02.006] [Medline: 21521589]

13. Corley C, Cook D, Mikler A, Singh K. Using web and social media for influenza surveillance. Adv Exp Med Biol 2010;680:559-564 [FREE Full text] [doi: 10.1007/978-1-4419-5913-3 61] [Medline: 20865540]

14. Alessa A, Faezipour M. A review of influenza detection and prediction through social networking sites. Theor Biol Med Model 2018 Feb 01;15(1):2 [FREE Full text] [doi: 10.1186/s12976-017-0074-5] [Medline: 29386017]

15. Yuan X, Crooks A. Examining online vaccination discussion and communities in Twitter. In: Proceedings of the 9th International Conference on Social Media and Society. New York, NY: Association for Computing Machinery; 2018 Presented at: 9th International Conference on Social Media and Society; July 18-20, 2018; Copenhagen, Denmark p. 197-206. [doi: 10.1145/3217804.3217912]

16. Mavragani A. Infodemiology and infoveillance: Scoping review. J Med Internet Res 2020 Apr 28;22(4):e16206 [FREE Full text] [doi: 10.2196/16206] [Medline: 32310818]

17. McKee M, Cole K, Hurst L, Aldridge RW, Horton R. The other Twitter revolution: How social media are helping to monitor the NHS reforms. BMJ 2011 Feb 16;342:d948. [doi: 10.1136/bmj.d948] [Medline: 21325389]

18. van Dijck J. The Culture of Connectivity: A Critical History of Social Media. Oxford, UK: Oxford University Press; 2013.

19. Neumark Y, Flum L, Lopez-Quintero C, Shtarkshall R. Quality of online health information about oral contraceptives from Hebrew-language websites. Isr J Health Policy Res 2012 Sep 24;1(1):38 [FREE Full text] [doi: 10.1186/2045-4015-1-38] [Medline: 23006798]

20. Moorhead SA, Hazlett DE, Harrison L, Carroll JK, Irwin A, Hoving C. A new dimension of health care: Systematic review of the uses, benefits, and limitations of social media for health communication. J Med Internet Res 2013 Apr 23;15(4):e85 [FREE Full text] [doi: 10.2196/jmir.1933] [Medline: 23615206]

21. Brodie M, Flournoy RE, Altman DE, Blendon RJ, Benson JM, Rosenbaum MD. Health information, the internet, and the digital divide. Health Aff (Millwood) 2000;19(6):255-265. [doi: 10.1377/hlthaff.19.6.255] [Medline: 11192412]

22. Neuhauser L, Kreps GL. Rethinking communication in the eHealth era. J Health Psychol 2003 Jan;8(1):7-23. [doi: 10.1177/1359105303008001426] [Medline: 22113897]

23. Grajales FJ, Sheps S, Ho K, Novak-Lauscher H, Eysenbach G. Social media: A review and tutorial of applications in medicine and health care. J Med Internet Res 2014 Feb 11;16(2):e13 [FREE Full text] [doi: 10.2196/jmir.2912] [Medline: 24518354]

24. Dixon G. Social media as a platform for science and health engagement: Challenges and opportunities. Isr J Health Policy Res 2016;5:57 [FREE Full text] [doi: 10.1186/s13584-016-0114-3] [Medline: 27895894]

25. Wu L, Morstatter F, Carley KM, Liu H. Misinformation in social media. SIGKDD Explor Newsl 2019 Nov 26;21(2):80-90. [doi: $10.1145 / 3373464.3373475$ ]

26. Eysenbach G. How to fight an infodemic: The four pillars of infodemic management. J Med Internet Res 2020 Jun 29;22(6):e21820 [FREE Full text] [doi: 10.2196/21820] [Medline: 32589589] 
27. Ahmed N, Quinn SC, Hancock GR, Freimuth VS, Jamison A. Social media use and influenza vaccine uptake among White and African American adults. Vaccine 2018 Nov 26;36(49):7556-7561. [doi: 10.1016/j.vaccine.2018.10.049] [Medline: 30389192]

28. Schulz PJ, Wu Y, An S, Chen F. Social influences on influenza vaccination decision among senior citizens in Taiwan, South Korea, and Switzerland. Front Commun 2019 Dec 13;4:1-13 [FREE Full text] [doi: 10.3389/fcomm.2019.00074]

29. Maci SM. Discourse strategies of fake news in the anti-vax campaign. Lingue Culture Mediazioni 2019 Nov 12;6(1):15-43 [FREE Full text] [doi: 10.7358/lcm-2019-001-maci]

30. Barello S, Falcó-Pegueroles A, Rosa D, Tolotti A, Graffigna G, Bonetti L. The psychosocial impact of flu influenza pandemics on healthcare workers and lessons learnt for the COVID-19 emergency: A rapid review. Int J Public Health 2020 Sep;65(7):1205-1216 [FREE Full text] [doi: 10.1007/s00038-020-01463-7] [Medline: 32888048]

31. Jones DS. History in a crisis - Lessons for Covid-19. N Engl J Med 2020 Apr 30;382(18):1681-1683. [doi: 10.1056/NEJMp2004361] [Medline: 32163699]

32. Chong YY, Cheng HY, Chan HYL, Chien WT, Wong SYS. COVID-19 pandemic, infodemic and the role of eHealth literacy. Int J Nurs Stud 2020 Aug;108:103644 [FREE Full text] [doi: 10.1016/j.ijnurstu.2020.103644] [Medline: 32447127]

33. Solomon DA, Sherman AC, Kanjilal S. Influenza in the COVID-19 era. JAMA 2020 Oct 06;324(13):1342-1343. [doi: 10.1001/jama.2020.14661] [Medline: 32797145]

34. Massey PM, Leader A, Yom-Tov E, Budenz A, Fisher K, Klassen AC. Applying multiple data collection tools to quantify human papillomavirus vaccine communication on Twitter. J Med Internet Res 2016 Dec 05;18(12):e318 [FREE Full text] [doi: 10.2196/jmir.6670] [Medline: 27919863]

35. Henrich NJ. Increasing pandemic vaccination rates with effective communication. Hum Vaccin 2011 Jun;7(6):663-666. [doi: 10.4161/hv.7.6.15007] [Medline: 21445004]

36. Lama Y, Hu D, Jamison A, Quinn SC, Broniatowski DA. Characterizing trends in human papillomavirus vaccine discourse on Reddit (2007-2015): An observational study. JMIR Public Health Surveill 2019 Mar 27;5(1):e12480 [FREE Full text] [doi: 10.2196/12480] [Medline: 30916662]

37. 2019-2020 US flu season: Preliminary in-season burden estimates. Centers for Disease Control and Prevention. 2020. URL: https://www.cdc.gov/flu/about/burden/preliminary-in-season-estimates.htm [accessed 2021-03-09]

38. Israel: Internet usage, broadband and telecommunications reports. Internet World Stats. 2020. URL: https://www. internetworldstats.com/me/il.htm [accessed 2021-03-09]

39. Social media stats: Israel. StatCounter. URL: https://gs.statcounter.com/social-media-stats/all/israel [accessed 2021-03-09]

40. Livni G, Chodik G, Yaari A, Tirosh N, Ashkenazi S. Attitudes, knowledge and factors related to acceptance of influenza vaccine by pediatric healthcare workers. J Pediatr Infect Dis 2015 Jul 28;03(02):111-117. [doi: 10.1055/s-0035-1556979]

41. Larson HJ, Jarrett C, Schulz WS, Chaudhuri M, Zhou Y, Dube E, SAGE Working Group on Vaccine Hesitancy. Measuring vaccine hesitancy: The development of a survey tool. Vaccine 2015 Aug 14;33(34):4165-4175 [FREE Full text] [doi: 10.1016/j.vaccine.2015.04.037] [Medline: 25896384]

42. Smith CJ, Fox ZV. The use and abuse of hypothesis tests: How to present P values. Phlebology 2010 Jun;25(3):107-112. [doi: 10.1258/phleb.2010.009094] [Medline: 20483859]

43. Shmueli G, Yahav I. The forest or the trees? Tackling Simpson's paradox with classification trees. Prod Oper Manag 2017 Dec 27;27(4):696-716. [doi: 10.1111/poms.12819]

44. Rokach L, Maimon O. Decision trees. In: Maimon O, Rokach L, editors. Data Mining and Knowledge Discovery Handbook. Boston, MA: Springer; 2005:165-192.

45. Using R and psych for personality and psychological research. Personality Project. 2020. URL: http://personality-project. org/r/psych/ [accessed 2021-03-09]

46. Subirana I, Sanz H, Vila J. Building bivariate tables: The compareGroups package for R. J Stat Softw 2014 May;57(12):1-16 [FREE Full text] [doi: 10.18637/jss.v057.i12]

47. rpart v4.1-15. RDocumentation. 2019. URL: https://www.rdocumentation.org/packages/rpart/versions/4.1-15 [accessed 2021-03-09]

48. Milborrow S. rpart.plot: Plot 'rpart' models: An enhanced version of 'plot.rpart'. The Comprehensive R Archive Network. 2020 Sep 17. URL: https://CRAN.R-project.org/package=rpart.plot [accessed 2021-03-09]

49. Eysenbach G. Improving the quality of web surveys: The Checklist for Reporting Results of Internet E-Surveys (CHERRIES). J Med Internet Res 2004 Sep 29;6(3):e34 [FREE Full text] [doi: 10.2196/jmir.6.3.e34] [Medline: 15471760]

50. von Elm E, Altman DG, Egger M, Pocock SJ, Gøtzsche PC, Vandenbroucke JP, STROBE Initiative. The Strengthening the Reporting of Observational Studies in Epidemiology (STROBE) statement: Guidelines for reporting observational studies. PLoS Med 2007 Oct 16;4(10):e296 [FREE Full text] [doi: 10.1371/journal.pmed.0040296] [Medline: 17941714]

51. Vandenbroucke JP, von Elm E, Altman DG, Gøtzsche PC, Mulrow CD, Pocock SJ, STROBE Initiative. Strengthening the Reporting of Observational Studies in Epidemiology (STROBE): Explanation and elaboration. PLoS Med 2007 Oct 16;4(10):e297 [FREE Full text] [doi: 10.1371/journal.pmed.0040297] [Medline: 17941715]

52. Barkat A. Average salary in Israel falls to NIS 11,459. Globes. 2020 Aug 04. URL: https://en.globes.co.il/en/ article-average-salary-in-israel-falls-to-nis-11459-1001338212 [accessed 2021-03-09] 
53. Tvizer I. Health report: Worst flu epidemic in decade. Ynet News. 2020 Jan 06. URL: https://www.ynetnews.com/ health science/article/S1kM9axlI [accessed 2021-03-09]

54. Martin N. How social media has changed how we consume news. Forbes. 2018 Nov 30. URL: https://www.forbes.com/ sites/nicolemartin1/2018/11/30/how-social-media-has-changed-how-we-consume-news/ [accessed 2021-03-09]

55. Brossard D. New media landscapes and the science information consumer. Proc Natl Acad Sci U S A 2013 Aug 20;110 Suppl 3:14096-14101 [FREE Full text] [doi: 10.1073/pnas.1212744110] [Medline: 23940316]

56. DeVito M, Birnholtz J, Hancock J. Platforms, people, and perception: Using affordances to understand self-presentation on social media. In: Proceedings of the 20th ACM Conference on Computer-Supported Cooperative Work and Social Computing. New York, NY: Association for Computing Machinery; 2017 Presented at: 20th ACM Conference on Computer-Supported Cooperative Work and Social Computing; February 25-March 1, 2017; Portland, OR p. $740-754$. [doi: $10.1145 / 2998181.2998192]$

57. Benis A, Barak Barkan R, Sela T, Harel N. Communication behavior changes between patients with diabetes and healthcare providers over 9 years: Retrospective cohort study. J Med Internet Res 2020 Aug 11;22(8):e17186 [FREE Full text] [doi: 10.2196/17186] [Medline: 32648555$]$

58. Ting DSW, Carin L, Dzau V, Wong TY. Digital technology and COVID-19. Nat Med 2020 Apr;26(4):459-461 [FREE Full text] [doi: 10.1038/s41591-020-0824-5] [Medline: 32284618]

59. Barrios JM, Hochberg Y. Risk Perception Through the Lens of Politics in the Time of the COVID-19 Pandemic. Cambridge, MA: National Bureau of Economic Research; 2020 Apr. URL: https://www.nber.org/system/files/working papers/w27008/ w27008.pdf [accessed 2021-03-09]

60. Van Bavel JJ, Baicker K, Boggio PS, Capraro V, Cichocka A, Cikara M, et al. Using social and behavioural science to support COVID-19 pandemic response. Nat Hum Behav 2020 May;4(5):460-471. [doi: 10.1038/s41562-020-0884-z] [Medline: 32355299]

61. Dhir A, Kaur P, Chen S, Pallesen S. Antecedents and consequences of social media fatigue. Int J Inf Manage 2019 Oct;48:193-202. [doi: 10.1016/j.ijinfomgt.2019.05.021]

62. Stieglitz S, Bunker D, Mirbabaie M, Ehnis C. Sense-making in social media during extreme events. J Conting Crisis Manage 2017 Aug 18;26(1):4-15 [FREE Full text] [doi: 10.1111/1468-5973.12193]

63. Ali KF, Whitebridge S, Jamal MH, Alsafy M, Atkin SL. Perceptions, knowledge, and behaviors related to COVID-19 among social media users: Cross-sectional study. J Med Internet Res 2020 Sep 08;22(9):e19913 [FREE Full text] [doi: 10.2196/19913] [Medline: $\underline{32841153]}$

64. Ashkenazi S, Livni G, Klein A, Kremer N, Havlin A, Berkowitz O. The relationship between parental source of information and knowledge about measles / measles vaccine and vaccine hesitancy. Vaccine 2020 Oct 27;38(46):7292-7298. [doi: 10.1016/j.vaccine.2020.09.044] [Medline: 32981777]

65. Shen K, Namazova-Baranova L, Yang Y, Wong GWK, Rosenwasser LJ, Rodewald LE, Global Pediatric Pulmonology Alliance (GPPA) Council, et al. Global Pediatric Pulmonology Alliance recommendation to strengthen prevention of pediatric seasonal influenza under COVID-19 pandemic. World J Pediatr 2020 Oct;16(5):433-437 [FREE Full text] [doi: 10.1007/s12519-020-00389-7] [Medline: 32920745]

66. Adlhoch C, Pebody R. What to expect for the influenza season 2020/21 with the ongoing COVID-19 pandemic in the World Health Organization European Region. Euro Surveill 2020 Oct;25(42):1-3 [FREE Full text] [doi: 10.2807/1560-7917.ES.2020.25.42.2001816] [Medline: 33094719]

67. Reukers DFM, Marbus SD, Smit H, Schneeberger P, Donker G, van der Hoek W, et al. Media reports as a source for monitoring impact of influenza on hospital care: Qualitative content analysis. JMIR Public Health Surveill 2020 Mar 04;6(1):e14627 [FREE Full text] [doi: 10.2196/14627] [Medline: 32130197]

68. Smailhodzic E, Hooijsma W, Boonstra A, Langley DJ. Social media use in healthcare: A systematic review of effects on patients and on their relationship with healthcare professionals. BMC Health Serv Res 2016 Aug 26;16:442 [FREE Full text] [doi: 10.1186/s12913-016-1691-0] [Medline: 27562728]

69. Shanahan T, Tran TP, Taylor EC. Getting to know you: Social media personalization as a means of enhancing brand loyalty and perceived quality. J Retailing and Consum Serv 2019 Mar;47:57-65. [doi: 10.1016/j.jretconser.2018.10.007]

\section{Abbreviations}

CHERRIES: Checklist for Reporting Results of Internet E-Surveys

HMO: health maintenance organization

SNS: social networking service

STROBE: Strengthening the Reporting of Observational Studies in Epidemiology

WHO: World Health Organization 
Edited by G Eysenbach; submitted 23.11.20; peer-reviewed by A Seidmann, DLG Rodrigues; comments to author 19.12.20; revised version received 28.12.20; accepted 01.03.21; published 16.03.21

Please cite as:

Benis A, Khodos A, Ran S, Levner E, Ashkenazi S

Social Media Engagement and Influenza Vaccination During the COVID-19 Pandemic: Cross-sectional Survey Study

J Med Internet Res 2021;23(3):e25977

URL: https://www.jmir.org/2021/3/e25977

doi: $10.2196 / 25977$

PMID: 33651709

(C)Arriel Benis, Anna Khodos, Sivan Ran, Eugene Levner, Shai Ashkenazi. Originally published in the Journal of Medical Internet Research (http://www.jmir.org), 16.03.2021. This is an open-access article distributed under the terms of the Creative Commons Attribution License (https://creativecommons.org/licenses/by/4.0/), which permits unrestricted use, distribution, and reproduction in any medium, provided the original work, first published in the Journal of Medical Internet Research, is properly cited. The complete bibliographic information, a link to the original publication on http://www.jmir.org/, as well as this copyright and license information must be included. 